stairs by circumducting and swinging the limbs at the hips. He gets downstairs by holding on to the balustrades and coming down sideways or, better still, by descending backwards. I imagine that the cause of the deformity was gonorrhœal rheumatism, though I obtained no history of gonorrhoea from the patient. The condition of the joints found on operating rather strengthens that opinion. I unfortunately did not obtain photographs of the condition before operating. Liverpool.

\section{UNUSUAL INJURIES CAUSED BY LIGHTNING} STROKE.

By R. H. E. Kraggs, M.R.C.S. Eng., J.P., GOVERNMENT MEDICAL OFFICER, TRINIDAD, WEST INDIES.

ON Oct. 17th a coolie at work in an open cane-field was killed by a flash of lightning. I was within 500 yards of the spot at the time and saw the flash, which was a multiple discharge descending and returning several times. I saw the man about fifteen minutes after the occurrence; he was quite dead and there was no rigidity. There was a lacerated wound of the right ear, which bad been almost torn off in an upward direction, and the hair of the head, worn long after the coolie custom, appeared to have been shaved off the right side in a vertical direction for a space of about six inches by two. There was a small abrasion on the right shoulder over the acromion process. These were all the external wounds found on a minute examination of the body, but the interest of the case appeared when, at a later stage, I opened the head. Sanious fluid was then observed running from the dependent nostril, and rigor mortis, sixteen hours after death, was very marked. A large hæmatoma had developed over the right parietal region, and on reflecting the scalp an extensive fracture of the skall was found. It started as a fine fissure from the left side near the parietal eminence, crossing transversely to the right side, and extending into the base. On removing the calvarinm and viewing it by transmitted light fine fissures were seen radiating from the main fracture across the right parietal bone. There was an excess of cerebro-spinal fluid. The surface of the brain was injected a bright pink, and the vessels of the meninges were gorged with fluid blood. The staining was most marked in the arachnoid in the neighbourhood of the brain fissures. The brain itself was abnormally soft, not from decomposition, but there was no laceration of its substance, nor was there any staining of the deeper tissues. Having removed the brain the fracture could be traced running across the middle fossa, then through the orbital plate of the frontal and the cribriform plate of the ethmoid-hence the bleeding from the nose. All the other organs of the body were healthy, nor was there any thoracic or abdominal injury. The heart was stopped in diastole and the blood fluid, but a few post-mortem clots had begun to form. The nature of the injuries and the fact that a felt hat which he had on at the time was blown several feet away and badly torn point to the conclusion that an upward discharge passed through his body, and as these upward discharges usually cause most damage to buildings the unusual and extensive head injuries may be accounted for. Notwithstanding our frequent and violent storms, death by lightning stroke is comparatively rare. A fellow labourer a few yards off received a severe shock; his senses were blunted and there were left external strabismus and dilatation and insensibility of the pupil, and acute conjunctivitis (of the left eye only) followed. Under treatment-cocaine bromide and exclusion of light-these symptoms passed off and he was none the worse for his close shave.

Couva, Trinidad, West Indies.

Royal British Nurses' Association.--The first sessional lecture of the season was delivered at 17, Old Cavendish-street, on Friday, Nov. 16th, before an appreciative audi nce by Mrs. Hughes of Kersall, Manchester, the subject being "Why Trained Nurses break down in Health." The chair was taken at 8 P.M. by Dr. Gage-Brown, C.M.G. An interesting discussion took place at the conclusion of the lecture on the varions points raised of special interest to nurses.

\section{A eftirtur}

\section{H O S P I T A L P R A C T I CE, BRITISH AND FOREIGN.}

Nulla autem est alia pro certo noscendi via, nisi quamplurimas et moz. borum et dissectionum historias, tum aliorum tum proprias collectas habere, et inter se comparare.-MorgagnI De Sed. et Caus. Morb., lib. iv. Procmium.

\section{VICTORIA HOSPITAL FOR SICK CHILDREN, CHELSEA.}

INFLAMED AND IRREDUCIBLE OMPHALOCELE OR COX GENITAL UMBILTCAL HERNIA ; OPERATION ; DEATH ; REMARKS.

(Under the care of Mr. D'ARCr Power.)

CASES of irreducible congenital umbilical hernia are not frequently met with, and as the condition is so rare the medical attendant is, perhaps, not quite ready to treat the condition with the promptitude which it demands. He may find that there are no symptoms of strangulation, and hopes that the swelling will disappear without operation; it does not do so, and the child dies in two or three days from peri. tonitis. It is to be remembered that this hernia differs from others in the same situation as regards the coverings of the sac. Those which are formed of the same material as the umbilical cord soon lose their vascularity and die, so that adhesion of the sac to the contents takes place very soon after birth, even if no adhesions had formed in utero. The hernia is early irreducible, and soon covered by a decomposing envelope. Much responsibility therefore rests on the medical man who first sees a child suffering from this condition, for taxis must be tried as soon as possible, followed by operation if not successful. There must be no waiting for symptoms of strangulation When vomiting comes on it is usually a sign of peritonitis, and the prognosis is then extremely bad. We are indebted for the notes of the case to Mr. C. S. Pantin, house surgeon.

A male infant aged two days was admitted to the Victoria Hospital for Sick Children, Chelsea, on Aug. 29th, with a tumour involving the proximal portion of the umbilical cord. The swelling was oval, of a lemon yellow colour, and opaque. It was covered with a funnel-shaped collar of healthy skin, which terminated abruptly in the umbilical cord. The remains of the umbilical cord attached to the under surface of the tumour were gangrenous and offensive. There was no difficulty in recognising the tumour as an omphalocele in a state of acnte inflammation and when taxis was applied its contents gurgled, but it proved to be quite irreducible. The child was healthy and free from any other defect; the bowels had been openec three times since birth, but the infant had been sick twice on the day of admission to hospital. Mr. Power therefore deter. mined to operate. He made an incision over the front of the tumour to avoid its gangrenous under surface. The incision showed that the wall of the sac was very thick and tough, and that its opacity was due to a thick layer of yellow lymph. The sac wall was so closely connected with the intestine which it surrounded that it could only be separates by gently peeling it off with the finger-nail. The intestine revealed by turning back the sac consisted of a mass matted together by tough layers of lymph, the vermiform appendix alone being recognisable. The mass was gradually unravelled until it became clear that it consisted of the crcum, with the vermiform appendix and portions of the ileum and colon, about eight inches of intestine in all. The gut was very greatly congested and the cæcum felt hard and thickened, but no part of it was gangrenous. There were firm attachments between the intestines and the umbilical ring at the point where they left the abdominal cavity. The adhesions were removed, the intestines were separated from each other, and, as moderate pressure failed to pass them through the umbilicus, the abdominal wall was laid open in the middle line for a short distance. The sac was then cut through at its collar of healthy skin and removed. The intestines were washed first in a hot solntion of carbolic acid ( 1 in 40), afterwards with boiled water, and they were then put into the 
peritoneal cavity, the cæcam, on account of its hardened and contracted condition, being the most difficult to replace. The wound was loosely closed with sutures of horsehair and silver, and antiseptic dressings were applied. The greatest care was taken throughout the operation to save the patient from shock by keecing the limbs and chest wrapped up and by laying him upon a hot-water bed. He rallied quickly from the collapse of the operation, but hiccough and romiting set in, so that it was necessary to feed him with nutrient enemata. The infant died twentyfour hours later. Some slight general peritonitis was found at the necropsy, and the bowel which had been contained in the hernia was seen to be greatly thickened.

Remarks by Mr. D'ARcy Pow ER. - This is the second case of strangulated omphalocele which has come under my notice. The first one, recorded and depicted in vol xxxix. of the Pathological Society's Transactions, also proved fatal. There is no more reason why these cases should be hopeless than an ordinary case of strangulated inguinal hernia, for the same treatment is applicable to both forms of rupture. There seems to be a prejudice against making any attempt at taxis in congenital umbilical hernia, though there is no doubt that if it be applied early the gut can in many cases be put into the abdominal cavity. If taxis be delayed, on the other hand, the slight inflammation attending the separation of the umbilical cord becomes greatly exaggerated, involves the sac with its contents, and soon spreads to the peritoneum. It is then too late to do anything, and the child dies. Farly taxis is called for in these cases, and the greatest care should be taken to prevent the cord becoming septic during the process of its separation. The surgeon should perform an abdominal section as soon as he has satisfied himself that taxis is useless, and he should remember that every minute he delays jeopardises a successful result, for the inflammatory processes in young children are very rapid. I proposed in the present case to remove the intestine contained in the sac bad it proved to be gangrenous, and to unite the proximal and distal portions at the nearest healthy parts; but, as the gut was only congested, I was spared the necessity of performing the more serious operation.

\section{SUSSEX COUNTY HOSPITAL.}

A CASE OF TUBERCULOSIS ; AN EUIA ; PYREXIA ; ENIARGED IIVER AND SPLEEN ; ASCITES; JAUNDICE.

(Under the care of Dr. A. J. RICHARDSON.)

IT is frequently impossible to diagnose a general tubercalosis, especially early in the disease. The following account is that of a case in which it was especially difficult to make a diagnosis during any stage of the illness, and in which the occurrence of jaundice and pyrexia with splenic enlargement present unusual symptoms. Dr. Richardson, to whom we are indebted for the notes of the case, refers to somewhat similar cases in his remarks.

A man forty-two years of age came to the out-patient department of the Sussex County Hospital on Dec. 14th, 1893, complaining of "aching all over." $\mathrm{He}$ had been gradually failing in health for about a month. He had bad influenza two years previously. He was suffering from slight cough and a little night sweating, but there was no hæmoptysis. His appetite was very bad; the tongue was densely white stippled, and the bowels were confined. Nothing abnormal was noticed in the heart or lungs. He was very anæmic, and the spleen was enlarged. He had always lived in Brighton and had never had ague. He was ordered two grains of quinine thrice daily and an aloin pill.

Jan. 11th, 1894, the hæmoglobin was 50 per cent.; there was no optic neuritis or retinal bæmorrhage; cup deeply marked. On Feb. 22ad he discontinued attendance, feeling nearly well, and went to work for seven weeks.

On May 17th he again came to the hospital complaining of retching and loss of appetite; the tongue was very white, and the bowels were rather loose. There were no cardiac bruits, even on lying down. Rhonchi were audible over both lungs, and although the spleen conld not be felt it gave an enlarged area of percussion dulness. The pulse was of low tension; the urine was intensely acid, dark orange in colour, and free from albumen. There was no clouding on heating, but a few drops of acetic acid then added gave a distinct cloud, probably due to mucin. He was admitted as an in-patient on June 18th. The temperature was $101^{\circ} \mathrm{F}$., the pulse 136 , and the respiration 18 . There was flattening at both apices, but no dulness. Sibilant rhonchi were heard over the front of the chest, with rales in the supra-clavicular fossæ. Crepitations were audible at both bases. The liver edge was three inches below the ribs, the surface being smooth. The spleen was enlarged; there were numerous petechiæ over the abdomen, legs, and arms. The patient had a very sallow aspect, but was not jaundiced. The hæmoglobin was 30 per cent. and the red corpuscles 60 per cent. There was no increase in the white corpuscles. No sputa could be obtained in which to search for bacilli. The sp. gr. of the urine was 1026, acid; no albumen was present. On June 19th the temperature reached $1036^{\circ}$; it began to fall on the 21st, and by the 23rd was normal. Two days later the spleen was notably smaller. On the 26 th the temperature reached $99^{\circ}$ in the evening. The spleen was a finger's breadth below the ribs. The temperature continued to rise until July $4 \mathrm{th}$, when it reached $103.8^{\circ}$ in the evening. and the spleen was three fingers' breadth below the ribs. On the 13th he perspired very freely, and the temperature fell to $97^{\circ}$, the spleen being distinctly smaller. On the $17 \mathrm{th}$ the spleen could not be felt. On the 23 rd there was severe pain in the left bypochondriac region. The next day there was ascites; the temperature was $100.6^{\circ}$. The note on Aug. 16th was as follows: "The teniperature has varied since the $24 \mathrm{th}$, sometimes reaching $102^{\circ}$. The patient is jaundiced; the urine and fæces bile stained; the ascites does not increase." He died on Aug. 26th.

Necropsy.-There were numerous old pleuritic adhesions, especially at the apices. Fluid was present in the left chest. Both apices were studded with small, hard, greyish bodies about the size of millet seeds. In the right apex there were cretaceous masses and small vomicæ. The remainder of the lungs was congested and odematous, but not studded with tubercle. The heart was large, flabby, and dilated; the muscular substance was softish and bile-stained. The tricuspid orifice admitted four fingers with ease, the mitral three. The aortic valves were competent, and the first part of the aorta was atheromatous. The abdomen was filled with clear, yellow fluid. Both layers of peritoneam were studded with minute grey granulations not so large as a pin's head. The intestines looked as though they had been freely sprinkled with wet white sand. The mesenteric glands were enlarged. The liver was very large, pale, and fatty. The gall-bladder was not distended. The spleen was much enlarged and soft. The kidneys were pale and fatty, and peeled smoothly. Although many sections were made at the necropsy through. the liver, spleen, and kidneys, no tubercles could be seen in them.

Remarts by Dr. RICHARDSON.-There are several points of interest in this case. At no time was there expectoration in which to make a satisfactory search for bacilli, although the house physician (Mr. Mallam), believing the case to be tuberculous, was most anxious to make such examination. Dr. Hollis (under whose care the patient was placed on admission to hospital on June 18th) particularly noted the large size and firm consistence of the spleen and the rapid changes in size which occurred coincidently with variations in temperature. The occurrence of jaundice in a case of tuberculosis was noted by Murchison in 1867. ${ }^{1}$ The liver in that case, although looking fatty, was firm and tough, and on microscopic examination was found to contain numerous miliary tubercles. Unfortunately no microscopic examination was made in the above case, but the liver was distinctly soft, with a rounded border. In 1875 Hilton Fagge noted a; similar case to Murchison's in the Guy's Hospital Reports. The fact that tubercles were found in the liver is the very pith of these cases. In Progrès Mrédical, 1892,2 Pilliet relates a case of tuberculous peritonitis and ascites with fatty degeneration of the liver; but in the above case the fatty liver may well be considered as connected with the old lung rather than the recent peritoneal lesions. Mr. Conolly Norman's case, although agreeing as to emaciation, sallowness, jaundice, and ascites, yet differs inasmuch as there was a definite abdominal tumour. The difficalty, if not impossibility, of a certain diagnosis was great. Such a careful observer as Fagge, in the Reports quoted above, says that the concurrence of jaundice with ascites is met with in scarcely any disease but cirrhosis of the liver and cancer. The resemblance of the case to Banti's splenomegaly with cirrhosis hepatis ${ }^{+}$was striking. Thus the anæmia with splenic tumefaction was an early sign, followed later by ascites, in the absence of history of alcoholism, syphilis, or malaria.

1 Diseases of the Licer, second edition, p. 246.
2 Ahstracted in Virchow's Jahresbericht, 1893.

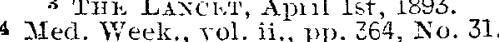

